\title{
Educational needs of Japan's dementia care workforce: results of a national online survey
}

\author{
By Michael J. AnNEAR ${ }^{1,2,3}$, Fumi Nagasawa ${ }^{3}$, KanO TERAWAKI $^{3}$, \\ FUYUKO NAGAREKAWA ${ }^{3}$, XIN GAO ${ }^{3} \mathcal{E}$ JUNKO OTANI ${ }^{3}$
}

\begin{abstract}
Dementia prevalence is increasing in Japan commensurate with population ageing. This study addresses the paucity of research concerning the dementia education needs of Japanese health workers who care for older adults. A random sample of 117 aged care workers was generated from government lists of institutions and services across eight regions of Japan. Volunteer respondents completed an online survey concerning perceptions of dementia, professional educational needs and demographic information. Japanese aged care workers identified a high prevalence of dementia among their clients and acknowledged the value of professional education; however, they only reported moderate levels of dementia knowledge and confidence with care provision. Educational preferences included learning about non-pharmacological treatments for behavioural and psychological symptoms of dementia, workshop and mentor-based programmes, and incentivising education

${ }^{1}$ Michael J. Annear, Department of Health and Physical Education, International Christian University, Tokyo, Japan

${ }^{2}$ Michael J. Annear, Faculty of Health, University of Tasmania, Australia

${ }^{3}$ Michael J. Annear, Fumi Nagasawa, Kano Terawaki, Fuyuko Nagarekawa, Xin Gao E Junko Otani,

Graduate School of Human Sciences, Osaka University, Japan
\end{abstract}


International Journal of Ageing and Later Life

through formal certification and targeting content to professions. This research may inform the development of educational interventions for aged care workers, which may ultimately affect care for people with dementia.

Keywords: dementia, aged care, professional education, Japan, national survey.

\section{Introduction}

This research explores the dementia education needs of a national sample of aged care professionals in Japan. Aged care describes a sector of the health system wherein paid professionals provide support for frail older adults who reside in the community or in nursing homes. Professional (or continuing) education refers to work-related training undertaken following the completion of one's preparatory disciplinary education (Queeney 2010). In the health sector, ongoing training is essential to ensure that best-evidence care and treatment are available to health consumers. Education potentially improves the care and treatment practices of health professionals by increasing self-efficacy (self-belief or confidence) in their capacity to take action to improve patient health. This is consistent with social cognitive theory (SCT) (Bandura 1986), which identifies self-efficacy as a pillar of clinical action. To provide effective professional education, however, it is necessary to understand the needs of target cohorts and areas of societal and epidemiological concern.

In the $21^{\text {st }}$ Century, dementia is emerging as one of the leading causes of death and disability in later life as individuals live longer than ever before (Ferri et al. 2006). Dementia is a progressive, neurodegenerative syndrome that is increasing in prevalence worldwide commensurate with population ageing (Kurrle et al. 2012). The clinical course of dementia varies considerably with physical, cognitive and behavioural symptoms that challenge diagnosis, treatment and care. While population ageing and advancements in preventive and curative medicine have triumphed over many of the maladies of the $19^{\text {th }}$ and $20^{\text {th }}$ centuries, a cure for dementia remains elusive. As there is currently no cure for the common forms of dementia, such as Alzheimer's disease and vascular 
dementia (Kurrle et al. 2012; Mitchell et al. 2009), it is necessary that health professionals understand best-evidence care and symptom management to provide patients with the best quality of life possible as the condition progresses.

As age is the primary risk factor for dementia, countries that are experiencing rapid population ageing, such as Japan, can expect significant increases in the prevalence of the condition in the coming decades (Ferri et al. 2006). Japan sits at the vanguard of population ageing due to historically low levels of fertility and mortality. In fact, it has been referred to as a super-ageing society due to the pace of demographic change relative to similarly developed countries (Muramatsu \& Akiyama 2011). Muramatsu and Akiyama report that by 2030 one in every three Japanese people will be aged 65 years or older, while the Japanese Ministry of Health, Labour and Welfare (2014) estimates that there will be 7 million diagnosed cases of dementia in the country by 2050. Japan's response to this challenge will arguably have global ramifications. Japanese experiences, policies and practices may inform strategies to respond to population ageing and dementia in other regions of the world. A recent observational study of Japanese aged care revealed that there are many world-leading approaches to the care of older persons within the Japanese health system that can inform global care practices (Annear et al. 2016d), including a focus on nutritional quality and physical rehabilitation. However, due to projections for unprecedented population increases in dementia and current high rates of Alzheimer's disease and vascular dementia (Ferri et al. 2006; Meguro et al. 2002), measures are required to ascertain the educational needs of professional aged care workers as a precursor to the development of targeted education.

Internationally, there is growing evidence for the importance of professional education within the health and aged care sectors. Forsetlund and colleagues conducted a Cochrane review in 2009 to explore the findings of 81 randomised controlled studies of workplace educational interventions within the health sector (Forsetlund et al. 2009). Among their findings, Forsetlund et al. reported that mixed modes of professional education, including educational meetings and workshops, significantly improved health professional practice and patient outcomes. In 2006, Downs et al. 
International Journal of Ageing and Later Life

conducted a randomised controlled study in the United Kingdom to assess the efficacy of dementia education for improving detection rates in primary care settings (Downs et al. 2006). Downs and colleagues reported that both computer-aided educational tools and face-to-face workshops significantly improved the rates of dementia diagnosis across 36 practice settings. In a reflection on the state of international dementia education research, Rampatige and colleagues noted that while there is emerging evidence for the efficacy of multi-faceted interventions, such programmes must be carefully targeted to respond to the learning needs of professionals in different clinical settings and cultural contexts (Rampatige et al. 2009). It appears that there is no one-size-fits-all approach to dementia education and that research must be undertaken in local contexts to carefully elucidate educational needs and knowledge deficiencies before interventions are administered.

Although there is mounting evidence for the efficacy of professional education within the health and aged care sectors, limited research has been published on professional educational needs related to aged and dementia care in Japan. Such research is necessary in order to develop evidence-based and targeted interventions to improve health professional practice and patient outcomes. A scoping review of the Japanese literature was undertaken to identify studies of professional education in aged and health care settings that have been completed in the last two decades. Only six studies that considered educational needs of Japanese health professionals or students who work with older people were identified since 1996. The majority of the studies were aimed at elucidating the technical instruction needs of narrowly defined clinical practices (such as oral care techniques for older adults or use of geriatric assessment tools) (Misawa et al. 2014; Yoshiyuki \& Kouno 2016) or conceptualising general workplace learning needs and experiences (such as professional coping in stressful environments) among health students (Kurabayashi 2014; Sakakura 1998), nurses (Furukawa et al. 2014) and clinicians (Honjyo \& Komada 2015). No studies that directly addressed the mental health or cognitive care education needs of the Japanese aged care workforce in the last 20 years were identified. A recent study conducted by the authors examined Japanese knowledge of dementia among a sample of 185 health students and educators as part of pilot testing for a dementia knowledge scale (Annear et al. 2016c). This study revealed preliminary evidence for 
a low level of understanding about dementia and fundamental misconceptions concerning the clinical course of the syndrome, symptomatology and the efficacy of pharmacological interventions for behavioural symptoms (Annear et al. 2016c). Such results suggest that there is potential educational need among those who will comprise the dementia care workforce in the coming years in Japan. A more general study of perceptions of working conditions among those who provide professional aged care in Japan revealed respondents' concerns about their capacity for caring for patients with dementia, self-assessed limits in biomedical knowledge and a perceived lack of caring skills (Okada 2010). Among a series of conclusions, the author recommended increased workplace training for certified care workers in Japan (Okada 2010).

The existing literature suggests that there is a gap in the collection of information about the dementia education needs of Japan's aged care workforce. The present study, therefore, examines self-reported education needs among a randomly selected, national sample of Japanese aged care professionals. The results of this research are intended to inform future development of dementia education interventions for these professionals, which may ultimately improve care and treatment practices for people with the condition.

\section{Methods}

\section{Design and Methods}

Between 25 June and 25 October 2016, an online survey of aged care professionals in Japan was administered. The survey was prepared using the Google Forms online platform. With the growing ubiquity of internet access, particularly in more developed countries, utilisation of online surveys as a replacement for paper or telephone surveys is increasingly common in health research (Smith et al. 2007). This mode of survey administration creates both challenges and benefits for researchers that should be weighed prior to administration. Perceived challenges include possible differences in responses among individuals with higher and lower levels of computer literacy, expectations for a lower overall response rate and concerns about reliability, validity and data security (Fricker et al. 2005; Shih \& Fan 2008). Specific advantages of online surveys include higher rates of survey 
International Journal of Ageing and Later Life

completion (where non-response can often be avoided through programming), cost and time savings compared to the use of mailed or telephone surveys, wider dissemination possibilities across large geographic areas, higher data quality as manual entry and associated error is unnecessary, and perceptions of greater anonymity in response (Smith et al. 2007; Van Gelder et al. 2010). Reasons for using an online survey in the present research included the accessibility of the approach for collaborative survey development, pilot testing and international administration, as well as expectations for higher rates of data quality (with no need for additional data entry). Due to the national scope of our study, the online survey also reduced the time to send and receive responses among a Japanese sample, which was a relevant consideration in the context of a 4-month data collection window.

The online survey contained sections on experiences in the care and treatment of dementia, confidence with dementia care, preferences concerning dementia education and demographic questions. Examples of four questions that were posed in the survey include the following: 1) how would you rate your current knowledge about dementia? 2) How would you rate your level of confidence about providing care for a person with dementia? 3) In which topic areas do you need to improve your knowledge about dementia? 4) Thinking about professional education, what is your preferred type of learning environment? All these questions were administered in Japanese. Likert scale, multiple choice and dichotomous response format options were utilised. A full list of survey items is presented in Appendix 1. The research was led by an experienced gerontologist and dementia care specialist (MA) with support from a team of bilingual Japanese academics with expertise in nursing, public health and the human sciences. The study was reviewed and approved by the Osaka University Human Research Ethics Committee (KS1604).

\section{Sampling, Selection and Recruitment}

Publically available lists of aged care facilities and service providers are accessible throughout Japan and maintained by prefectural governments. Five facility and service typologies were sampled for the study from these lists, including special homes for older people (nursing homes); geriatric hospitals (specialist facilities for chronically unwell older adults); health facilities for the elderly (nursing care and medical management services); 
respite/day services (short-term care support); and support/local management centres (community-based centres to support health management). These facilities and services represent the spectrum of long-term nursing care, specialist health care and community management for older adults who have diverse care requirements, including dementia. All geographic area typologies were included in the sampling frame of the study, including service providers in urban, regional and rural locations. Lists of aged care facilities were compiled for each of the eight regions of Japan using information from local prefecture governments. Within each of the eight regions of Japan, systematic sampling was used to randomly select 30 facilities from these lists. Facilities were then contacted by telephone by research assistants and a representative from the organisation was asked if they (or a nominated staff member) wished to participate in the study. Interested parties provided a contact email address for a clinical or administrative staff member. Occupational cohorts targeted in the study included a range of aged care professionals, such as nurses, care workers, physical therapists, clinical educators, trainees and administrative or managerial staff. Emails were then sent to potential respondents, providing information about the study and containing a link to the online survey. Potential respondents volunteered their participation and responses were anonymous. Respondents understood that consent for the inclusion of their data in the research was conditional upon their submission of the online survey.

\section{Analysis}

All analyses were conducted using SPSS (version 20.0) for Windows (IBM Corp 2011). Continuous data were initially screened for normality and the potential effects of outlier values, which revealed that the data were slightly negatively skewed, indicating the suitability of non-parametric tests of significance. Analyses were primarily descriptive, encompassing percentages and frequencies to elucidate dementia care experiences, educational needs and demographic information. Spearman's correlation was used to examine the potential relationship between self-reported knowledge and confidence in the care and treatment of dementia. Finally, cross-tabulations were performed to assess potentially significant relationships between previous dementia experiences (work, education and 
International Journal of Ageing and Later Life

familial care) and self-reported educational needs (course content, learning typology and motivation).

\section{Results}

\section{Sample and Response}

In total, 197 aged care facilities provided contact details for staff members and indicated their willingness to receive email communication concerning survey participation. Among this cohort, 117 participants completed the online survey between July and October 2016, accounting for a response rate of $59 \%$. No reasons were provided for non-participation as responses were anonymous once submitted online. The $5 \%$ trimmed means was checked against the true mean for continuous data and there was found to be no substantive influence from outlier values.

Concerning the demographic profile of respondents, the majority were from the Kansai region of Japan (encompassing the large cities of Osaka, Kyoto and Kobe), there was a relatively even gender split between male and female participants, and care workers were the most represented occupational cohort. Other occupational cohorts that responded to the survey are identified in Table 1, which include nurses, health students on placement, clinical educators, administrative and managerial staff, and other aged care workers (such as physical therapists). The majority of participants indicated that they had vocational or university training, previous dementia education experiences, and were directly involved in daily dementia care (see Table 1).

\section{Educational Needs Analysis}

National survey respondents reflected upon the prevalence of dementia in their workplaces and their experiences with professional education and dementia care and treatment. Respondents indicated that a large proportion of their clientele in aged care settings live with dementia. When estimating the prevalence of dementia, $76 \%$ of respondents considered that more than one out of every two of their clients experienced the condition. In the context of high levels of perceived dementia in Japanese aged care, there was also a high value placed on professional education, with the majority of respondents 
Table 1. Demographic profile of respondents $(N=117)$

\begin{tabular}{ll}
\hline Demographic information & Statistics \\
\hline Regional locations of respondents & \\
Hokkaido & $5(4.3 \%)$ \\
Tohoku & $3(2.6 \%)$ \\
Kanto & $16(13.7 \%)$ \\
Chubu & $5(4.3 \%)$ \\
Kansai & $80(68.4 \%)$ \\
Chugoku & $2(1.7 \%)$ \\
Shikoku & $3(2.6 \%)$ \\
Kyushu/Okinawa & $3(2.6 \%)$ \\
Gender & \\
Male & $61(52.1 \%)$ \\
Female & $56(47.9 \%)$ \\
Age & \\
Mean age (Standard deviation) & 56 years $(5.68)$ \\
Minimum & 47 years \\
Maximum & 70 years \\
Occupation & \\
Medical student (workplace training) & $1(0.9 \%)$ \\
University academic (clinical educator) & $1(0.9 \%)$ \\
Nurse & $6(5.1 \%)$ \\
Care worker & $74(63.2 \%)$ \\
Other aged care staff & $13(11.1 \%)$ \\
Other (including managerial or service staff) & $22(18.8 \%)$ \\
Highest qualification & \\
Elementary school & $1(0.9 \%)$ \\
High school & $14(12.0 \%)$ \\
Vocational training & $30(25.6 \%)$ \\
University undergraduate degree & $65(55.6 \%)$ \\
University postgraduate degree & $4(3.4 \%)$ \\
Other & $3(2.6 \%)$ \\
\hline &
\end{tabular}


International Journal of Ageing and Later Life

Table 1. (Continued)

\begin{tabular}{ll}
\hline Demographic information & Statistics \\
\hline Direct professional dementia care experience & \\
Yes & $65(55.6 \%)$ \\
No & $52(44.4 \%)$ \\
Previous dementia education experience & \\
Yes & $69(59.0 \%)$ \\
No & $48(41.0 \%)$ \\
Family member with dementia & \\
Yes & $41(35.0 \%)$ \\
No & $76(65.0 \%)$ \\
\hline
\end{tabular}

scoring the importance of continuing learning as "very important" (modal value of 5 on a 5-point Likert scale). In spite of the perceived prevalence of dementia and a high regard for professional education, self-rated knowledge of dementia and self-rated confidence in the provision of treatment and care were only rated as "moderate" (modal value of 3 on 5-point Likert scales). Correlation (Spearman) analysis of self-rated knowledge and self-rated confidence was undertaken. A statistically significant and strongly positive correlation was identified between self-assessed knowledge of dementia and confidence in the provision of dementia care and treatment among Japanese aged care professionals $(r=0.76, p<0.001, n=117)$.

Descriptive analyses of Japanese health professionals' dementia education needs revealed preferences for specific content, learning styles and motivation for participation. Among the desired content considered as important for enhancing understanding of dementia, the most frequently reported educational needs included learning about the non-pharmacological interventions for challenging behaviours (39\%), dementia pathology $(17 \%)$ and dementia causes and risk factors $(12 \%)$. When considering the delivery of dementia education, the majority of respondents indicated their preference for learning in a group workshop or seminar setting (58\%) followed by individual mentoring from a senior colleague or dementia expert $(16 \%)$. Finally, when articulating their motivation for dementia education, the most commonly reported incentives for participation included accessing diverse content about the condition and its care $(34 \%)$, recognition of 
learning and achievement in the form of certification (20\%) and targeted content tailored to the needs of particular aged care professions (17\%).

Finally, a series of cross-tabulations were undertaken to investigate potentially significant associations between previous dementia experiences and reported dementia education needs. A significant relationship was identified between prior dementia education and motivation for professional education. Respondents with previous formal dementia education experience expressed significantly greater motivation to undertake diverse education that covered all aspects of the condition than those who did not have previous education in this area $(p<0.05)$. Thus, previous dementia education appeared to act as a potential motivating factor for the intention to participate in future dementia training across a broad scope of the condition and its care and treatment. There were no significant associations between direct dementia care experiences or family care experiences and any modality of dementia education needs (Table 2).

\section{Discussion}

A dementia education needs analysis was conducted with a national, random sample of 117 aged care professionals from eight regions of Japan. Respondent cohorts represented in greatest number included individuals from the Kansai region, professional care workers and those with undergraduate or vocational qualifications. Many respondents also had previous experiences of direct dementia care, formal dementia education and family care for relatives with the condition - suggesting some level of pre-existing understanding prior to online survey participation. The majority of respondents $(76.9 \%)$ estimated that $50 \%$ or more of their aged care clients had dementia, which indicates a perception of high prevalence of the condition within Japanese institutional settings. This estimation is congruent with known global prevalence within aged care settings reported internationally (Ferri et al. 2006) and the high incidence of the condition that has been reported in Japan (Meguro et al. 2002), although relatively limited research on prevalence has been conducted on populations older than 80 years who live in institutional settings (Dodge et al. 2012). It also suggests that dementia in Japanese aged care facilities is currently at a high baseline and that pressures associated with the condition can be expected to increase in the coming decades as Japan continues to age as a society. Understanding dementia prevalence is challenging as 
International Journal of Ageing and Later Life

Table 2. Dementia experiences and education needs $(N=117)$

\begin{tabular}{|c|c|}
\hline Dementia experiences and education needs & Statistics \\
\hline \multicolumn{2}{|l|}{ Estimated proportion of clients with dementia $(n)$} \\
\hline Less than $25 \%$ & $4(3.4 \%)$ \\
\hline $25-50 \%$ & $23(19.7 \%)$ \\
\hline $50-75 \%$ & $28(23.9 \%)$ \\
\hline Greater than $75 \%$ & $62(53.0 \%)$ \\
\hline \multicolumn{2}{|l|}{ Importance of professional/continuing education/5 } \\
\hline Mean (Standard deviation) & $4.73(0.54)$ \\
\hline Median & 5.00 \\
\hline Mode & 5.00 \\
\hline \multicolumn{2}{|l|}{ Self-rated knowledge about dementia/5 } \\
\hline Mean (Standard deviation) & $3.15(0.67)$ \\
\hline Median & 3.00 \\
\hline Mode & 3.00 \\
\hline \multicolumn{2}{|l|}{ Self-rated confidence in dementia care $/ 5$} \\
\hline Mean (Standard deviation) & $2.97(0.74)$ \\
\hline Median & 3.00 \\
\hline Mode & 3.00 \\
\hline \multicolumn{2}{|l|}{ Dementia education needs $(n)$} \\
\hline Care for people with dementia & $10(8.5 \%)$ \\
\hline Dementia causes and risk factors & $14(12.0 \%)$ \\
\hline Dementia pathology & $20(17.1 \%)$ \\
\hline Dementia symptoms & $4(3.4 \%)$ \\
\hline $\begin{array}{l}\text { Non-pharmacological interventions for behavioural } \\
\text { symptoms }\end{array}$ & $45(38.5 \%)$ \\
\hline Pharmacological treatment options for people with dementia & $8(6.8 \%)$ \\
\hline Prevention of dementia & $13(11.1 \%)$ \\
\hline Others & $3(2.6 \%)$ \\
\hline \multicolumn{2}{|l|}{ Preferred learning mode $(n)$} \\
\hline Group workshop or seminar & $68(58.1 \%)$ \\
\hline One-to-one mentoring with a senior colleague or expert & $19(16.2 \%)$ \\
\hline Self-paced online course & $10(8.5 \%)$ \\
\hline
\end{tabular}


Table 2. (Continued)

\begin{tabular}{ll}
\hline Dementia experiences and education needs & Statistics \\
\hline Self-paced distance learning (not online) & $2(1.7 \%)$ \\
University or other tertiary institution classes & $14(12.0 \%)$ \\
Other & $4(3.4 \%)$ \\
Motivation for professional education $(n)$ & \\
A certificate of completion or achievement & $23(19.7 \%)$ \\
Access to a group where I could ask students or tutors & $4(3.4 \%)$ \\
questions & $20(17.1 \%)$ \\
Content targeted to the learning needs of my profession & $2(1.7 \%)$ \\
Contribution to professional accreditation & $11(9.4 \%)$ \\
Multimedia content, including video and audio & $40(34.2 \%)$ \\
Diverse content covering all aspects of dementia & $6(5.1 \%)$ \\
treatment and care & $11(9.4 \%)$ \\
Regular tests/quizzes to check my progress & \\
Freely accessible content &
\end{tabular}

under-diagnosis of the condition is common, even in developed countries, and symptoms can often mimic other conditions, including depression or mild cognitive impairment (MCI) (Kurrle et al. 2012). Despite some uncertainty, projections for dementia in Japan suggest major increases in prevalence and incidence in the coming four decades (Dodge et al. 2012), which (in the absence of curative treatments) will necessitate improved awareness and understanding of the condition among the aged care workforce. The nature of dementia presentations in Japan may also be more complicated than in other developed countries, with evidence suggesting comparatively higher levels of vascular dementia in conjunction with already prevalent Alzheimer's disease (Ikeda et al. 2001; Yanagihara 2002). Thus, the future of dementia in Japanese aged care is likely to present unique challenges related to both an increasing prevalence and complicated presentation.

The online survey respondents were well educated, with $85 \%$ reporting that they had at least vocational training for work in aged care and $59 \%$ reporting that they were qualified with a bachelor's degree or higher. This high level of education, particularly at bachelor's degree 
International Journal of Ageing and Later Life

level, potentially reflects the seniority of respondents within their organisations. Relatedly, the data revealed a significant association between previous dementia education (as part of course or workshop participation) and motivation for further professional education. It appears that professional education in the health sector may be a self-reinforcing or virtuous cycle whereby previous experiences of formal learning provide the impetus for individuals to seek out future educational opportunities (Wolters 2003). Relevant and best-evidence education in the health workplace may help to re-engage lower skilled workers with learning and support motivation by allowing them to experience achievement, self-efficacy, comradery and goal fulfilment (Keller 2008). Opportunities for professional education have previously been reported as an important factor in the retention of workforce participants in the health sector (Willis-Shattuck et al. 2008) where financial rewards are often lacking (particularly for lower skilled workers) and the demands of the role can be challenging. Turnover rates among aged care staff in many developed countries are typically higher than other sectors, and Japan is no exception to this. Government research indicates that one out of every five aged care workers in Japan leaves their organisation annually and $56 \%$ regularly consider leaving their job (Ministry of Health, Labour \& Welfare 2016). Professional education in areas such as dementia care may help incentivise greater workplace engagement in this challenging environment.

Respondents placed a high value on professional education in the context of their roles within the aged care sector (modal score of 5 on a 5-point Likert scale). Considering the progressive, neurodegenerative course of dementia (Kurrle et al. 2012; Mitchell et al. 2009), it is understandable that continued learning in this complex environment was valued by health care workers. Emerging research concerning the efficacy of professional education about older adult health shows that workplace learning can improve clinical outcomes for patients. For example, a recent systematic review of educational interventions among clinical participants showed that singular or mixed modes of professional education (including courses, conferences, lectures, workshops, seminars and symposia) can facilitate significant, positive changes in learning and, consequently, improve patient outcomes (Forsetlund et al. 2009). Evidence from the United Kingdom also supports improved detection and diagnoses of dementia, with implications for improved care, 
following professional education among those who provide high levels of care for older adults (Downs et al. 2006). In countries such as Australia, dementia education programmes are well established with specialised courses offered at universities and by workplace education providers, including degree courses, massive open online courses, and dementia education and advisory services (King et al. 2014). While dementia education interventions are yet to be trialled with members of the aged care workforce in Japan, evidence from other developed countries in the Asia-Pacific region suggests that significant impacts on care and treatment behaviour and patient outcomes may be expected.

Despite a high regard for professional education among aged care workers, self-reported knowledge about dementia and confidence with care and treatment were only moderate (modal score of 3 on 5-point Likert scales), indicating respondents' reservations about their level of self-efficacy in effectively managing the condition in their workplace. There is a strong, positive correlation between self-rated knowledge of dementia and self-rated confidence in the provision of care and treatment. This aligns with the literature concerning SCT, which asserts that self-efficacy (self-confidence in clinical abilities) is an important attribute for determining clinical action taking (Bandura 1986, 2004), including the capacity to provide effective care for a person with dementia in an institutional setting. Although causality was not assessed in this study, it can be hy pothesised that improving knowledge through professional education may have the capacity to enhance clinical selfconfidence in the care and treatment of a person with dementia. This may potentially lead to better health and quality of life outcomes for people living with this degenerative condition. Internationally, there is evidence from medical education and dietetics that improving professionals' knowledge plays an important role in increasing self-efficacy (e.g. care and treatment behaviour) and that an increase in both of these parameters leads to measurably better care and treatment for patients (Ghaffarifar et al. 2015; Stark et al. 2011). Hypotheses concerning the potential outcomes of dementia education in the workplace should be tested with an educational intervention that examines baseline knowledge of the health care workforce, knowledge change following education and any resultant changes to clinical behaviour and patient outcomes. 
International Journal of Ageing and Later Life

When members of the Japanese aged care workforce reflected on their dementia education needs, preferences were identified for content, educational style and motivating factors. Aged care professionals showed preferences for learning a breadth of content about dementia with specific focus on non-pharmacological interventions for the management of behavioural symptoms. The mode of educational delivery considered most efficacious was a group workshop or seminar, potentially augmented with mentoring from senior colleagues or dementia experts. Finally, respondents indicated that participation in professional dementia education should be incentivised with the recognition of learning in the form of certification for course attainment and completion. Each of these preferences is considered below.

Aged care workers' preferences for learning about non-pharmacological approaches to the management of dementia-related behaviours reflect the challenges of caring professions. As dementia is a progressive, neurodegenerative condition that causes significant cognitive changes, challenging behavioural and psychological symptoms of dementia (BPSD) frequently result from the underlying pathology. Common BPSD include emotional disturbances, delusions and abnormal thought patterns, agitation or aggression, visual hallucinations, wandering and changes in sleep patterns and appetites (Cerejeira et al. 2012). All of these changes can prompt unpredictable behaviours in the person with dementia. Such symptoms create difficulties for carers and family members and may threaten the safety of those who provide support as well as the person with dementia. BPSD can be addressed with either pharmacological or non-pharmacological treatments. Pharmacological interventions for BPSD (particularly the prescription of antipsychotic medications) are known to carry significant risks and are associated with deleterious side effects, including stroke, delirium and death (Guthrie, Clark \& McCowan 2010). For this reason, carers and family members are often interested in less harmful alternatives. Non-pharmacological interventions for BPSD are considered comparatively safer and involve a range of activities, communication strategies and counselling techniques that have proven efficacy in reducing the severity and frequency of BPSD (Douglas et al. 2004). Examples of non-pharmacological interventions that have been used to address BPSD include cognitive behaviour therapy, reminiscence therapy, environmental modification, support groups, music therapy, pet therapy, 
multi-sensory therapy, physical activity and others (Douglas et al. 2004; Janzen et al. 2013). Learning about such approaches can help aged care providers to support their clients with dementia without increasing the risks associated with medical management.

Japanese aged care professionals indicated that their preferred mode of education was group workshop or seminar and discussions with mentors or dementia experts. This suggests that respondents value education that can be provided at their place of work, face-to-face and in the context of other learners. Intervention research conducted in the United Kingdom has shown that participation in dementia education workshops undertaken at aged care facilities significantly enhances the rates of detection of dementia professional staff (Downs et al. 2006). Australian research has also shown that workplace dementia education improves knowledge and attitudes among clinical trainees, including medical and nursing students (Annear et al. 2016b). These findings suggest that connecting education with the direct experience of dementia care provides an optimal setting for learning. In Europe and Australia, teaching aged care facilities (TACFs) combine educational and institutional facilities to provide on-site learning opportunities for staff and trainees concerning geriatric health and care (Annear et al. 2014). Such facilities may also be effective in Japan, although there are currently no examples of the development or evaluation of such initiatives. Concerning preferences for collective learning, inter-cultural education research has previously reported that group activity is often preferred for learners from East Asian nations, including Japan, due to cultural preferences for communal activity, classroom harmony and shared learning experiences that reflect wider societal values (Nguyen, Terlouw \& Pilot 2006). Respondent preferences for collective and interpersonal modes of workplace dementia education are also consistent with the reflective practice model of organisational learning (Schon 1983). Within this framework, researchers have asserted that collective work, peer dialogue and reflection on practice among those who provide aged care services can be more effective in facilitating learning than formal modes of education (Börjesson et al. 2015; Nishikawa 2011). The effectiveness of collective workplace learning is theorised to be driven by the value that care workers place on shared and co-constructed knowledge at their place of work as a uniting organisational force. This contrasts with the privileged 
International Journal of Ageing and Later Life

knowledge of individual experts, which is sometimes perceived to undermine group learning (Börjesson et al. 2015). Japanese preferences for collective learning in the context of dementia education are potentially significant as increasing institutional endeavour has gone into the development of MOOCs. Such modes of education provide accessibility for distance learners and individuals without the means of attending university courses, but fail to account for preferences for and benefits of learning with peers in a group setting.

The final element of preferred dementia education addressed by Japanese aged care workers was the importance of incentivising education through recognition of learning (formal certification) and targeting content to the needs of professions (professional care workers, allied health workers, recreation officers, nurses, etc.). Globally, work in aged care settings is often characterised by low pay and status, manual labour, shift work, high staff turnover and limited opportunities for professional development (Annear et al. 2014; Hugo 2007; Ministry of Health, Labour \& Welfare 2016). There are also persistent hierarchies within the health professions of many developed countries, which often unfairly subordinate and devalue nursing and caring roles within the health care sector and wider society (Walker \& Holmes 2008). Providing formal recognition of learning through certification may help affirm the value of aged care professionals and provide them with a record of achievement to support their career development. Such strategies can play an important role in improving care worker motivation and, in turn, supporting better care for clients with dementia. Research conducted in Japan has shown that professional identity and image are important motivational factors for people who work in aged care (Hotta et al. 2009). Provision of certification for relevant learning may provide an opportunity to enhance identity for such workers and improve the image of the profession. As populations in more developed countries continue to age and expectations for quality of care in later life increase, there will need to be a commensurate increase in the value placed on those who provide care in institutional settings. The growing prevalence of complex conditions, such as dementia, will necessitate that the Japanese workforce is well versed in best-evidence care, appropriately compensated and valued by the health care sector and society. 


\section{Limitations, Implications and Future Research}

The collection of national data from aged care facilities and service providers in Japan was not without challenges. A number of aged care facilities and service providers listed in each prefecture did not have a website or email contact information and the data presented herein represent a subset of aged care facilities that have access to electronic communication technology (a limitation of online surveys generally). Furthermore, the largest response cohort came from the Kansai area (encompassing the large cities of Osaka, Kyoto and Kobe). It was apparent from the contact between research assistants and potential respondents that there was a degree of provincialism in respondents' intention to support (or not support) research efforts from a large public university based in Kansai. As aged care providers within each region of Japan were randomly selected (using a systematic sampling approach), it was not possible to differentiate rural and urban professionals as part of the present analysis. Future research studies could implement a cluster sampling approach within each region of Japan to explore rural and urban differences in dementia education needs or dementia knowledge if significant geographic differences are hypothesised. Although a response rate of $59 \%$ was achieved in this study, work could also be undertaken to capture the educational needs of groups who are typically disinclined to participate in survey research, including those with lower levels of workplace self-efficacy, clinical expertise or education. Future in-depth research using interview or focus group methodologies among purposively selected aged care service providers may be helpful to fully assess the diversity of educational needs within the sector. In contradistinction to studies conducted in other developed countries (Annear et al. 2016a), the gender of respondents of this research was closely matched. This could indicate a more equitable gender balance in Japanese aged care when compared to other countries in which females are the dominant workforce participants (Alzheimer's Disease International 2015). This thesis, however, is not supported by Japanese government data, which show that females comprise up to $80 \%$ of professional carers for older adults (Ministry of Health, Labour \& Welfare 2014) consistent with the proportion of the aged care workforce in other countries. The nature of the present sample may reflect the dominance of male professionals in senior clinical and administrative roles within the sector, 
International Journal of Ageing and Later Life

making them more likely to respond to the online survey as a person of authority within their organisations. Due to the increasing demands for aged care in Japan, it is also likely that there will be growing demands for male participation in service industries that have traditionally been the preserve of female workers as the demography of Japan undergoes rapid change (Muramatsu \& Akiyama 2011). Despite these limitations, this study is the first of its kind to use a diverse Japanese sample to ascertain the dementia education needs of a population of aged care workers at a time when the condition is growing in prevalence. The systematic sampling approach that was used across diverse facilities and service providers ensures a degree of representativeness, although replication with larger random samples is recommended to verify these results.

\section{Conclusion}

This study provides evidence of the dementia education needs among a national sample of Japanese aged care professionals. The data show that Japanese aged care workers consider dementia to be prevalent in aged care and value the role that professional education can play in enhancing their understanding of the condition and improving institutional care for their clients. When conceptualising their needs for dementia education, respondents require content that addresses a breadth of information about the condition (from risk factors and underlying pathology through psychosocial aspects of care). Of greatest concern for aged care professionals is a desire to improve their understanding of non-pharmacological approaches to managing the challenging behaviours associated with the progression of dementia. Professional education courses should be administered for greatest effect by utilising workplace workshops and seminars augmented with expert mentoring. Such education should also be incentivised by targeting workshops to the needs of specific professional groups and providing recognition of learning in the form of certification. This study represents the first time that professional dementia education needs have been described across the Japanese aged care sector. It is anticipated that these results will be used by academics, clinical educators and policy specialists to inform the development of workplace education programmes in the Japanese aged care sector that aim to improve care quality and treatment practices for people with dementia. As Japan is at 
the vanguard of global population ageing and as age is the greatest risk factor for dementia, responses to the prevalence of the condition in this super-ageing society will provide salient lessons for the rest of the developed world.

\section{Acknowledgements}

The initiation of this research and Japanese data collection were supported by a National Health and Medical Research Council and Australian Research Council Dementia Research Development Fellowship [Grant number 1099245].

\section{Corresponding Author}

Michael J. Annear, Department of Health and Physical Education, International Christian University, 3-10-2, Osawa 3-chome, Mitaka, Tokyo 1818585, Japan. Telephone: +81 42233 3833. Email: michael.annear@gmail. com

\section{References}

Alzheimer's Disease International. (2015). Women in dementia: A global research review. London, United Kingdom: Alzheimer's Disease International.

Annear, M., Eccleston, C., McInerney, F., Elliott, K., Toye, C., Tranter, B. \& Robinson, A. (2016a). A new standard in dementia knowledge measurement: Comparative validation of the Dementia Knowledge Assessment Scale and the Alzheimer's Disease Knowledge Scale. Journal of the American Geriatrics Society 64(6): 1329-1334.

Annear, M., Lea, E., Lo, A., Tierney, L. \& Robinson, A. (2016b). Encountering aged care: A mixed methods investigation of medical students' clinical placement experiences. BMC Geriatrics 16(1): 38-51.

Annear, M., Lea, E. \& Robinson, A. (2014). Are care workers appropriate mentors for nursing students in residential aged care? BMC Nursing 13(1): 44-52.

Annear, M., Otani, J. \& Li, J. (2016c). A Japanese-language Dementia Knowledge Assessment Scale: Psychometric performance, and health 
International Journal of Ageing and Later Life

student and professional understanding. Geriatrics \& Gerontology International. Online Early View. DOI: 10.1111/ggi.12911.

Annear, M. J., Otani, J. \& Sun, J. (2016d). Experiences of Japanese aged care: The pursuit of optimal health and cultural engagement. Age and Ageing 45(6): 753-756.

Bandura, A. (1986). Social foundations of thought and action: A social cognitive theory. Thousand Oaks, CA: Prentice-Hall.

Bandura, A. (2004). Health promotion by social cognitive means. Health Education \& Behavior 31(2): 143-164.

Börjesson, U., Cedersund, E. \& Bengtsson, S. (2015). Reflection in action: Implications for care work. Reflective Practice 16(2): 285-295.

Cerejeira, J., Lagarto, L. \& Mukaetova-Ladinska, E. (2012). Behavioral and psychological symptoms of dementia. Frontiers in Neurology 3(73): $1-21$.

Dodge, H. H., Buracchio, T. J., Fisher, G. G., Kiyohara, Y., Meguro, K., Tanizaki, Y. \& Kaye, J. A. (2012). Trends in the prevalence of dementia in Japan. International Journal of Alzheimer's Disease 2012(1): 1-11.

Douglas, S., James, I. \& Ballard, C. (2004). Non-pharmacological interventions in dementia. Advances in Psychiatric Treatment 10(3): 171-177.

Downs, M., Turner, S., Bryans, M., Wilcock, J., Keady, J., Levin, E. \& Iliffe, S. (2006). Effectiveness of educational interventions in improving detection and management of dementia in primary care: Cluster randomised controlled study. British Medical Journal, 332(7543): 692-700.

Ferri, C. P., Prince, M., Brayne, C., Brodaty, H., Fratiglioni, L., Ganguli, M. \& Huang, Y. (2006). Global prevalence of dementia: A Delphi consensus study. The Lancet 366(9503): 2112-2117.

Forsetlund, L., Bjorndal, A., Rashidian, A., Jamtvedt, G., O'Brien, M. A., Wolf, F. \& Oxman, A. (2009). Continuing education meetings and workshops: Effects on professional practice and health care outcomes. Cochrane Database of Systematic Reviews 15(2): 1-113.

Fricker, S., Galesic, M., Tourangeau, R. \& Yan, T. (2005). An experimental comparison of web and telephone surveys. Public Opinion Quarterly 69(3): 370-392.

Furukawa, N., Tsuboi, K., Asai, E., Usami, R., Okumura, M., Umezu, M. \& Ono, S. (2014). Present conditions and problems of nursing care activities at long-term care wards, and the way of education support. Bulletin of Gifu Prefectural College of Nursing 14(1), 121-130. 
Ghaffarifar, S., Ghofranipour, F., Ahmadi, F., Khoshbaten, M. \& Sallis, C. (2015). The causal relationship between interns' knowledge and self-efficacy and their value in predicting the interns' communication behavior with patients. International Journal of Community Based Nursing and Midwifery 3(4): 263-271.

Guthrie, B., Clark, S. A. \& McCowan, C. (2010). The burden of psychotropic drug prescribing in people with dementia: A population database study. Age and Ageing 39(5): 637-642.

Honjyo, T. \& Komada, R. (2015). The effect of psychological education for health care workers with a focus on assertion training. Research of the Nippon Functional Nursing Association 30: 127-132.

Hotta, K., Okuno, J., Tomura, S. \& Yanagi, H. (2009). Determinant factors encouraging work motivation: A study of care staff working in health services facilities for elderly people. Japanese Journal of Public Health 56(12): 863-874.

Hugo, G. (2007). Contextualising the "crisis in aged care" in Australia: A demographic perspective. Australian Journal of Social Issues 42(2): 169-175.

IBM Corp. (2011). IBM SPSS Statistics for Windows, Version 20.0. Armonk, New York: IBM Corp.

Ikeda, M., Hokoishi, K., Maki, N., Nebu, A., Tachibana, N., Komori, K. \& Tanabe, H. (2001). Increased prevalence of vascular dementia in Japan: A community-based epidemiological study. Neurology 57(5): 839-844.

Janzen, S., Zecevic, A. A., Kloseck, M. \& Orange, J. (2013). Managing agitation using non-pharmacological interventions for seniors with dementia. American Journal of Alzheimer's Disease and Other Dementias 28(5): 524-532.

Keller, J. (2008). First principles of motivation to learn and e3-learning. Distance Education 29(2): 175-185.

King, C., Robinson, A. \& Vickers, J. (2014). Online education: Targeted MOOC captivates students. Nature 505(7481): 26.

Kurabayashi, S. (2014). The skill training for public health nurses education: Students' learning in health education practice. Takasaki Health and Welfare University Bulletin 13: 43-51.

Kurrle, S., Brodaty, H. \& Hogarth, R. (2012). Physical comorbidities of dementia. New York: Cambridge University Press.

Meguro, K., Ishii, H., Yamaguchi, S., Ishizaki, J., Shimada, M., Sato, M. \& Yamadori, A. (2002). Prevalence of dementia and dementing diseases in Japan: The Tajiri project. Archives of Neurology 59(7): 1109-1114. 
International Journal of Ageing and Later Life

Ministry of Health, Labour \& Welfare (2014). White paper: The present situation and trends of ageing and environment. Available on http://www8. cao.go.jp/ (Accessed: February 21, 2017).

Ministry of Health, Labour \& Welfare. (2016). Outline of Heisei 20year employment trend survey results: Outline of results. Available on http://www.mhlw.go.jp (Accessed: January 17, 2017).

Misawa, M., Uehara, T., Yamazaki, H. \& Ozaki, T. (2014). A study of dental health services for homebound elderly people: Home-visit nursing care stations. Journal of the Japanese Society of Dental Medical Management 48(4): 277-282.

Mitchell, S. L., Teno, J. M., Kiely, D. K., Shaffer, M. L., Jones, R. N., Prigerson, H. G. \& Hamel, M. B. (2009). The clinical course of advanced dementia. New England Journal of Medicine 361(16): 1529-1538.

Muramatsu, N. \& Akiyama, H. (2011). Japan: Super-aging society preparing for the future. The Gerontologist 51(4): 425-432.

Nguyen, P. M., Terlouw, C. \& Pilot, A. (2006). Culturally appropriate pedagogy: The case of group learning in a Confucian Heritage Culture context. Intercultural Education 17(1): 1-19.

Nishikawa, M. (2011). (Re)defining care workers as knowledge workers. Gender, Work \& Organization 18(1): 113-136.

Okada, F. (2010). The role and challenges of professional organizations in care work specialist training: Survey of members of the Niigata Association of Certified Care Workers' awareness of training needs. Japanese Journal of Health and Welfare 10(2): 4-9.

Queeney, D. S. (2010). Continuing professional education. In C. Kasworm, A. Rose \& J. Ross-Gordon (eds.), Handbook of adult and continuing education (pp. 375-391). Thousand Oaks, CA: Sage.

Rampatige, R., Dunt, D., Doyle, C., Day, S. \& van Dort, P. (2009). The effect of continuing professional education on health care outcomes: Lessons for dementia care. International Psychogeriatrics 21(Suppl 1): 34-43.

Sakakura, E. (1998). Educational effects of interviewing conducted by students: Study on nursing teaching methods for the elderly. Bulletin of Hokkaido University Medical College Department 11: 79-84.

Schon, D. (1983). The reflective practicioner: How professionals think in action. New York: Basic Books. 
Shih, T. \& Fan, X. (2008). Comparing response rates from web and mail surveys: A meta-analysis. Field Methods 20(3): 249-271.

Smith, B., Smith, T. C., Gray, G. C. \& Ryan, M. A. (2007). When epidemiology meets the Internet: Web-based surveys in the Millennium Cohort Study. American Journal of Epidemiology 166(11): 1345-1354.

Stark, C., Graham-Kiefer, M., Devine, C., Dollahite, J. \& Olson, C. (2011). Online course increases nutrition professionals' knowledge, skills, and self-efficacy in using an ecological approach to prevent childhood obesity. Journal of Nutrition Education and Behavior 43(5): 316-322.

Van Gelder, M. M., Bretveld, R. W. \& Roeleveld, N. (2010). Web-based questionnaires: The future in epidemiology? American Journal of Epidemiology 172(11):1292-1298.

Walker, K. \& Holmes, C. A. (2008). The "order of things": Tracing a history of the present through a re-reading of the past in nursing education. Contemporary Nurse 30(2), 106-118.

Willis-Shattuck, M., Bidwell, P., Thomas, S., Wyness, L., Blaauw, D. \& Ditlopo, P. (2008). Motivation and retention of health workers in developing countries: A systematic review. BMC Health Services Research 8(1): 247-255.

Wolters, C. A. (2003). Regulation of motivation: Evaluating an under-emphasized aspect of self-regulated learning. Educational Psychologist 38(4): 189-205.

Yanagihara, T. (2002). Vascular dementia in Japan. Annals of the New York Academy of Sciences 977(1): 24-28.

Yoshiyuki, N. \& Kouno, A. (2016). The effect of the educational program for preventive care service using comprehensive geriatric assessment to home-visiting nurses. Elderly Care 20(2): 47-56. 
International Journal of Ageing and Later Life

Appendix 1. Dementia education survey items [translated from Japanese to English]

\begin{tabular}{|c|c|}
\hline Survey item & Response format \\
\hline \multicolumn{2}{|l|}{ Dementia education questions } \\
\hline $\begin{array}{l}\text { Have you ever provided professional dementia } \\
\text { care to older adults within the aged care sector? }\end{array}$ & $\begin{array}{l}\text { Dichotomous response } \\
\text { (Yes/No) }\end{array}$ \\
\hline $\begin{array}{l}\text { Have you ever completed a professional training } \\
\text { course on dementia? }\end{array}$ & $\begin{array}{l}\text { Dichotomous response } \\
\text { (Yes/No) }\end{array}$ \\
\hline $\begin{array}{l}\text { How would you evaluate your current knowledge } \\
\text { of dementia? }\end{array}$ & Likert scale \\
\hline $\begin{array}{l}\text { How would you evaluate your level of confidence } \\
\text { about providing care for a person with dementia? }\end{array}$ & Likert scale \\
\hline $\begin{array}{l}\text { What proportion of your patients who are aged } \\
65 \text { years or older would you estimate to have a } \\
\text { cognitive impairment? }\end{array}$ & Multiple response option \\
\hline $\begin{array}{l}\text { What area do you consider as most needed to } \\
\text { improve your knowledge about dementia? }\end{array}$ & Multiple response option \\
\hline $\begin{array}{l}\text { How important is continuing/professional } \\
\text { education for your development as a health } \\
\text { professional? }\end{array}$ & Likert scale \\
\hline $\begin{array}{l}\text { Thinking about continuing/ professional educa- } \\
\text { tion, what is your preferred type of learning } \\
\text { environment? }\end{array}$ & Multiple response option \\
\hline \multicolumn{2}{|l|}{ Demographic information questions } \\
\hline $\begin{array}{l}\text { Which geographic area of Japan are you currently } \\
\text { working in? }\end{array}$ & Multiple response option \\
\hline When is your date of birth? & $\begin{array}{l}\text { Dropdown box selection } \\
\text { (calendar) }\end{array}$ \\
\hline What is your gender? & Multiple response option \\
\hline What is your current occupation? & Multiple response option \\
\hline $\begin{array}{l}\text { What is your highest completed educational } \\
\text { qualification? }\end{array}$ & Multiple response option \\
\hline $\begin{array}{l}\text { Have any of your immediate family members ever } \\
\text { been diagnosed with dementia? }\end{array}$ & $\begin{array}{l}\text { Dichotomous response } \\
\text { (Yes/No) }\end{array}$ \\
\hline
\end{tabular}

